\title{
El Agroturismo en sinergia con la preservación de los recursos culturales ancestrales. (El tejido de la fibra de cabuya en la comunidad de Nizag)
}

\author{
Agrotourism in synergy with the preservation of ancestral cultural resources. \\ (The weaving of cabuya fiber in the community of Nizag).
}

María Belén Bastidas Aráuz. ${ }^{1}$, Carlos Fernando Inga Aguagallo. ${ }^{2}$ \& Danilo Fernando Fernández. ${ }^{3}$

Abstract.

DOI: https://doi.org/10.33262/concienciadigital.v3i3.1.1365

Agrotourism as an alternative for the conservation of cultural heritage in the Yino communities of Ecuador, is part of a sustainable and sustainable model in search of economic, cultural and endogenous development of populations. In this sense, a research aimed at explaining the real conditions faced by women weavers of Nizag in their desire to promote an Agrotourism project linked to the elaboration of cabuya fiber handicrafts as an ancestral cultural resource of the population and the possible synergies is presented. that would generate in the socio-productive processes of the community. For this, a field work with a systemic approach was carried out, which analyzed the social, cultural and productive imbrications of the tourism project in the community, structuring a route and possible tourist packages, knowing the potential tourist demand in factors such as the origin of tourists, preferences, travel reasons, availability of time and resources to invest in the destination, and determine the problems and those involved for the construction of a value chain, all with the purpose of achieving social sustainability and the consolidation of the project in its real dimension without overestimating its benefits and not underestimating its potential.

Key Words: Agrotourism, Synergies, Cabuya handicrafts, cultural heritage, weaving women.

\section{Resumen}

El agroturismo como alternativa de conservación del patrimonio cultural en las comunidades andinas del Ecuador, forma parte de un modelo sostenible y sustentable en busca del desarrollo

\footnotetext{
${ }^{1}$ Escuela Superior Politécnica de Chimborazo, Chimborazo Ecuador, m_bastidas@espoch.edu.ec https://orcid.org/0000-0002-1746-7307

${ }^{2}$ Universidad Nacional de Chimborazo, Chimborazo Ecuador, cfinga@unach.edu.ec

(iD) https://orcid.org/0000-0003-1929-4427

${ }^{3}$ Escuela Superior Politécnica de Chimborazo, Chimborazo Ecuador, danilo.fernandez@espoch.edu.ec (iD) https://orcid.org/0000-0003-4929-9325
} 
económico, cultural y endógeno de estas poblaciones. En este sentido se platea una investigación orientada a explicar las reales condiciones que enfrentan las mujeres tejedoras de Nizag en su afán de fomentar un proyecto de Agroturismo vinculado a la elaboración de artesanías de fibra de cabuya como recurso cultural ancestral de la población y las posibles sinergias que generaría en los procesos socio productivos de la comunidad. Para ello se realizó un trabajo de campo con enfoque sistémico, que permitió analizar las imbricaciones sociales, culturales y productivas del proyecto turístico en la comunidad, estructurar una ruta y los posibles paquetes turísticos, conocer la potencial demanda turística en factores como el origen de los turistas, las preferencias, motivos de viaje, disponibilidad de tiempo y recursos a invertir en el destino, y determinar la problemática e involucrados para la construcción de una cadena de valor, todo ello con el propósito de alcanzar sostenibilidad social y la consolidación del proyecto en su real dimensión sin sobrestimar sus beneficios y tampoco subestimando su potencial.

Palabras Clave: Agroturismo, Sinergias, Artesanías de cabuya, patrimonio cultural, mujeres tejedoras.

\section{Introducción.}

\section{Los recursos Culturales Ancestrales}

Las culturas indígenas son una parte vital del mosaico contemporáneo de la diversidad étnica en el Ecuador, esto es especialmente evidente en la relación ancestral con la tierra, que se refleja en la cotidianidad de las comunidades campesinas y en la cantidad de formas de expresiones ancestrales que ocupan un lugar destacado en las creencias, y practicas sociales y culturales contemporáneas.

Recientemente muchos de estos sitios y formas de expresión cultural han sido reconocidos como recursos culturales ancestrales materiales e inmateriales, debido a acciones y políticas que garantizan, por un lado, conservar las costumbres, tradiciones y técnicas, y por otro, recuperar todo tipo de manifestaciones que permita la salvaguardia de los pueblos culturales y ancestrales como patrimonio inmaterial. En concurrencia, al artículo 34 de la Ley de Patrimonio Cultural del Ecuador en el artículo 4 dispone precautelar las expresiones y manifestaciones culturales (Congreso Nacional del Ecuador, 2004)

Sin embargo, la estabilización, protección, uso e interpretación de estos sitios de acuerdo con las teorías y modelos de conservación existentes han resultado ser difíciles; basado en el reconocimiento de que dichos lugares siguen siendo críticos para la identidad continua de los pueblos nativos y que muchos de estos sitios son visitados y disfrutados simultáneamente por turistas, su preservación y gestión respetuosa se han convertido en un tema relevante, oportuno y a veces controvertido.

Los esfuerzos para el rescate del patrimonio cultural, resultan infructuosos en tanto no se pueda poner en valor a los recursos y elementos que lo conforman, de ahí que se ha visto a la actividad turística como una alternativa de conservación, en función de su capacidad de ser el medio para el empoderamiento cultural de las comunidades, y para generar los recursos financieros para su autoconservación (Domínguez L, Batista R, \& Joseph L, 2014). 


\section{La sinergia del agroturismo y los recursos culturales ancestrales}

El Agroturismo se constituye en un espacio importante para la integración de los procesos culturales ancestrales en el desarrollo socio económico de la comunidad, esta actividad permite la construcción colectiva de opcionales para el descubrimiento de situaciones que pueden ser acertadamente utilizadas para la estructuración de un modelo vinculado a la cotidianidad y los valores intrínsecos de los habitantes con la finalidad de crear actividades alternativas para la generación de recursos incidiendo en la gestión del desarrollo de la comunidad y el entorno familiar (Jimenez, 2014).

Desde la perspectiva de los investigadores sociales, las manifestaciones agrícolas tradicionales guardan un importante contenido del patrimonio cultural de los pueblos, aspectos que deben ser recuperados y conservados como elementos que promuevan la identidad (Gómez E \& Gómez, 2006). Para los desarrolladores de actividades turísticas representan un insumo importante para ser aprovechado como experiencia turística vivencial, sostenible ambiental y económicamente, con el propósito de que los actores locales mejoren su calidad de vida; atendiendo eso sí, a los tres pilares básicos del turismo comunitario: (i) la centralidad analítica de las comunidades, (ii) el entendimiento de la actividad turística comunitaria como 'traducción' antes que como 'adaptación' al mercado, y (iii) que el turismo suponga un afianzamiento antes que una amenaza para las comunidades (Ruiz, Hernández, Coca, Cantero, \& Del Campo, 2008), como aspecto complementario al desarrollo del agroturismo comunitario, se considera necesario mencionar que, en la guía de turismo comunitario del Ecuador, la FETCE (2013) promueve además el turismo comunitario como el vínculo productivo en la actividad económica popular y solidaria, anteponiendo al ser humano como el actor principal del desarrollo.

Los aspectos señalados, permiten a la comunidad de Nizag la oportunidad de forjar emprendimientos con identidad, haciendo posible que sus habitantes aprovechen los recursos locales y los saberes ancestrales para mejorar su condición de vida.

En este caso particular se analiza la manufactura de artesanías de fibra de cabuya, cuyo proceso está estrechamente vinculado a los recursos naturales del entorno, elementos iconográficos que reflejan la identidad ancestral de la población y sobre todo a las labores agrícolas y familiares que las mujeres realizan cotidianamente, estos aspectos son especialmente valorados en las actividades relacionadas al turismo comunitario (Rodas, Donoso, \& Sanmartín, 2015). Con los aprendizajes alcanzado y la sistematización de la experiencia agroturística y de conservación del patrimonio cultural, se busca establecer generalizaciones que sistematizadas adecuadamente pueden ser utilizados y aprovechas, como referentes en otros territorios y entornos con condiciones similares.

Complementariamente, el turismo comunitario en sus diferentes manifestaciones, tiene un alto contenido de criterios antropológicos que buscan definir la interrelación de los elementos culturales y sociales que fundamentan la forma de vida al interior de las parcialidades autóctonas (Cedeño E, Pennington G, \& Matthews J, 2015), en este sentido, la conservación del patrimonio cultural pretende rescatar los hechos más trascendentales de estos grupos humanos que se manifiestan subjetivamente a través de sus costumbres y tradiciones para fortalecerles y evitar que se pierdan en tiempo, influenciadas por factores exógenos que contribuyen a su desgaste y extinción. 


\section{Metodología}

El trabajo propuesto tiene un enfoque sociológico, económico y sistémico, parte de los procesos sociales y los recursos culturales ancestrales, con el propósito de promover al agroturismo como una actividad productiva alternativa, adecuadamente estructurada y organizada. Se utilizó el método analítico que permitió descifrar las características de las actividades cotidianas y su relación con la cultura ancestral, específicamente relacionado a las imbricaciones de los procesos agrícolas y artesanales necesarios para la elaboración de artesanías de cabuya, con lo que fue posible realizar una síntesis que permitió la estructuración de una ruta turística cuyo propósito es el de hacer que el turista se integre de forma activa en el proceso, en un recorrido en el que aprenda e interiorice los conocimientos ancestrales y le sea posible entender e interrelacionarse con la comunidad. Para complementar el trabajo se estructura una cadena de valor del Proyecto de las artesanías de cabuya en la comunidad de Nizag, articulando los entornos y los actores en sus diferentes niveles y roles.

La información primaria se obtuvo a través de la observación directa en una investigación de campo, que implico la participación activa y permanente con la comunidad en todas las etapas de investigación, en este proceso se aplicaron entrevistas y encuestas a 60 socias pertenecientes a la corporación de Mujeres tejedoras de Nizag y a 365 visitantes que corresponden los turistas que realizaron la ruta Alausi - Sibambe, lugar donde prestan servicios turísticos la comunidad de Nizag,

La información secundaria, fue recopilada de diferentes fuentes bibliográficas, y datos estadísticos de trabajos relacionados a la comunidad de Nizag y vinculados al agroturismo, turismo comunitario y manejo y preservación de recursos culturales ancestrales. Para la estructuración de la ruta turística se tomaron en cuenta los procesos agrícolas del cultivo de la cabuya, el tratamiento de la fibra como materia prima y la elaboración de las artesanías en base a la fibra para el efecto se realizó un mapeo.

\section{Resultados}

\section{Diagnostico Turístico de la Comunidad de Nizag}

La parcialidad de Nizag, es una comunidad indígena de unas 360 familias, ubicada en el la parroquia La Matriz del cantón Alausí en la provincia de Chimborazo, se caracteriza por las peculiaridades biofísicas del territorio (varios pisos altitudinales en una extensión territorial muy pequeña) que hacen posible una producción agrícola de costa y sierra (PDOT Alausí, 2015).

Los orígenes étnicos de la población, forma de vida y cultura, mantienen cierto sincretismo y misterio que les da un carácter mágico (Urgiles P, 2016), convirtiéndole en un potencial turístico de importancia cultural frente a otras comunidades andinas con presencia indígena, a pesar de ello su desarrollo turístico depende en la actualidad de su vinculación con el producto tren, que es considerado un atractivo de categoría I. 
El desarrollo de la actividad turística en Nizag, ha sido objeto de intervención y promulgación de varias acciones de agentes externos a la comunidad, entre estas, se encuentra la Corporación de Turismo de Chimborazo (CORDTUCH), una entidad privado - comunitaria que promueve el turismo de base comunitaria en la provincia, sin embargo, han sido doce años de presencia de esta Corporación, y a decir de la comunidad de Nizag, no ha demostrado una intervención objetiva en el sostenimiento de la actividad turística (Bastidas A, 2012).

Así mismo, (Estrada A, 2015) refiere que, pese a la rehabilitación y operación de la ruta del tren Alausí - Sibambe, y la creación misma del sitio turístico conocido como Sibambe, la comunidad no ha podido obtener beneficios económicos ni sociales, ya que la coyuntura política de los Ferrocarriles del Ecuador Empresa Pública, ha direccionado a que en este lugar específicamente se realicen muestras de la culturalidad del sector, dejando que el turista conozca y participe de una muestra del folklor; mientras que la comunidad no participa de un verdadero desarrollo turístico comunitario.

Por otro lado, se han ejecutado una serie de propuestas de fomento turístico, que han sido diseñadas sin considerar las reales necesidades y problemas de los habitantes de la comunidad, prueba de ello es la gran colección de propuestas turísticas, vinculadas a la comunidad de Nizag y que se pueden encontrar en los repositorios de las instituciones de educación superior no solamente de la provincia de Chimborazo, sino también de otras universidades a nivel nacional. (Pilco C, 2015)

Como resultado de las innumerables intervenciones y la incidencia de organizaciones no gubernamentales y del Estado, en la comunidad de Nizag logró disponer de una casa albergue para el desarrollo del turismo, que generalmente se ha convertido en el sitio de permanencia de jóvenes pasantes evangélicos o de organizaciones de ayuda humanitaria. Otro uso que la comunidad realiza en esta infraestructura, es el desarrollo de actividades gremiales o de reuniones para la comunidad, y al no tener ingresos económicos, se ha convertido en un sitio que se encuentra en deterioro y pone en riesgo el colapso o no funcionamiento del lugar. (Bastidas A, 2012).

Con respecto la operación turística, las diferentes intervenciones a nivel público, privado y comunitario generaron paquetes turísticos para distintas modalidades y segmentos de turismo, sin embargo, la actividad es muy escasa y esporádica. Por otro lado, ha sido imposible realizar un análisis preciso de ingreso de turistas a la comunidad, por que no existe un registro sistémico de observatorio turístico.

El diagnóstico turístico de la comunidad de Nizag, reveló la necesidad de contar con un elemento integrador que potencialice la actividad turística, pero que, al mismo tiempo influya sinérgicamente con la cultura y la idiosincrasia de los pobladores de la comunidad.

\section{El tejido de fibra de cabuya.}

En el Ecuador, las técnicas artesanales tradicionales de carácter tangible del patrimonio inmaterial deben resguardar el "saber hacer" que se transmite de generación en generación, más que los objetos o productos de la actividad artesanal. Es así como la política pública de 
salvaguardia concerniente al patrimonio cultural inmaterial es aplicado a aquellos conocimientos aún presentes y que requieren ser preservados en el tiempo, precautelando la esencia del conocimiento y transmisión cultural, es decir, las distintas manifestaciones del patrimonio con categoría de registro denominado "Manifestaciones vigentes vulnerables" que son categorizadas con un nivel medio o alto de vulnerabilidad debido a la detección de amenazas en la transmisión de conocimientos, saberes, prácticas inherentes a la manifestación, entre otras (INPC (a), 2013).

En la comunidad de Nizag, a través de la Corporación de Mujeres Tejedoras, las técnicas artesanales y significado cultural están presentes en las artesanías tejidas de fibra de cabuya que confeccionan, siendo una actividad de rescate cultural (INPC (b), 2013), que como producto artesanal comerciable aún no representa rentabilidad, por sus características de elaboración, pero que sin embargo es el elemento tangible y más representativo de la comunidad que permite imbricar las actividades Agroturísticas con la cultura ancestral.

La Corporación de Mujeres Tejedoras de Nizag está conformada por un grupo de unos 60 miembros cuyas edades oscilan entre los 19 y 60 años, sin contar con las niñas menores de edad que aprenden el oficio y las mujeres mayores cuya actividad es más esporádica pero que, son la fuente de conocimiento ancestral más importante de la actividad (Bastidas A, 2012). En la actualidad han logrado consolidarse como Corporación, sin embargo se rigen a los estatutos de la comunidad. Con un alto nivel de gestión, es el grupo más activo en la organización y están en constantes procesos de capacitación y formación.

La Shigra, que es un bolso tejido $100 \%$ a mano, de fibra vegetal preparada y teñida artesanalmente, obtenida de las plantas denominadas Cabuya negra "Furcraea cabuya", y Cabuya blanca "Furcraea andina"; es el elemento más representativo de este tipo de artesanías, por la colorida representación iconográfica que presentan sus diseños, que de ninguna manera son productos planificados, sino que van surgiendo de la inspiración de las tejedoras a medida que los van realizando.

La confección de las Shigras implica un proceso muy interesante, cuyo contenido cultural, trasciende en el tiempo y el espacio. Inicia con la plantación de los cabuyos, para lo cual las mujeres, realizan tareas agrícolas específicas, el segundo paso es la recolección de las hojas y su preparación como materia prima (limpieza, teñido y secado), actividades que en sí, ya son una demostración de formas ancestrales del manejo y laboreo del suelo, y del tratamiento y pigmentación de la cabuya utilizados por los indígenas siglos atrás, actividades vivenciales dignas de ser mostradas a los visitantes.

Una vez obtenida la fibra de la cabuya, las mujeres realizan el tejido de la shigra (bolso artesanal) combinado esta actividad con el trabajo cotidiano, mientras pastorean el ganado, en las pausas de las labores agrícolas o del hogar y por las noches, no existe un lugar ni un tiempo específico, por lo que el visitante puede incorporarse en una gran cantidad de actividades vivenciales, que le permiten tener una experiencia altamente significativa y enriquecedora, como lo exige la demanda turística actual.

\section{Ruta y paquetes agroturísticos}

En base al proceso de elaboración de las artesanías de cabuya, y con la participación de la comunidad se estructuró una ruta agroturística, vinculada a la estación de Pistishi, lugar al que 
llegan los turistas en la ruta del Tren a la Nariz del Diablo. Se ha propuesto la ruta del sendero Pistishi - Nizag con una distancia de 6,27 km y una pendiente de +277 m.s.n.m. en su recorrido. en el que se encuentran cinco paradas para realizar actividades de interpretación turística y cultural. Esta ruta inicia en Pistishi (Nariz del Diablo) a una altitud de 1.866 m.s.n.m. y culmina en el sector de Nizag Alto a 2.143 m.s.n.m. (Figura 1). La señalética ${ }^{4}$ establecida para el sendero consta de un panel Informativo al inicio del sendero en el que se propone el nombre de la ruta, un mapa orientativo, los principales atractivos y la distancia a recorrer.

De la zonificación turística ${ }^{5}$ propuesta, para generar valor intrínseco a las prácticas agrícolas y culturales en la comunidad de Nizag, se han establecido las siguientes áreas: 1) Área de cultivo de la cabuya (que se encuentra principalmente en las laderas de los terrenos comunitarios), 2) Transformación de materia prima (cosecha de las hojas de cabuya, deshilado de fibras, secado, tinturado y distribución de la fibra de cabuya).

En cuanto a los paquetes turísticos, se establece un paquete que integra la convivencia cultural, atractivos turísticos naturales, gastronomía, ruta ferroviaria, entre otros. Los paquetes mencionados tienen como mercado objetivo los turistas nacionales y extranjeros, con tiempos de duración entre 1 y 3 días.

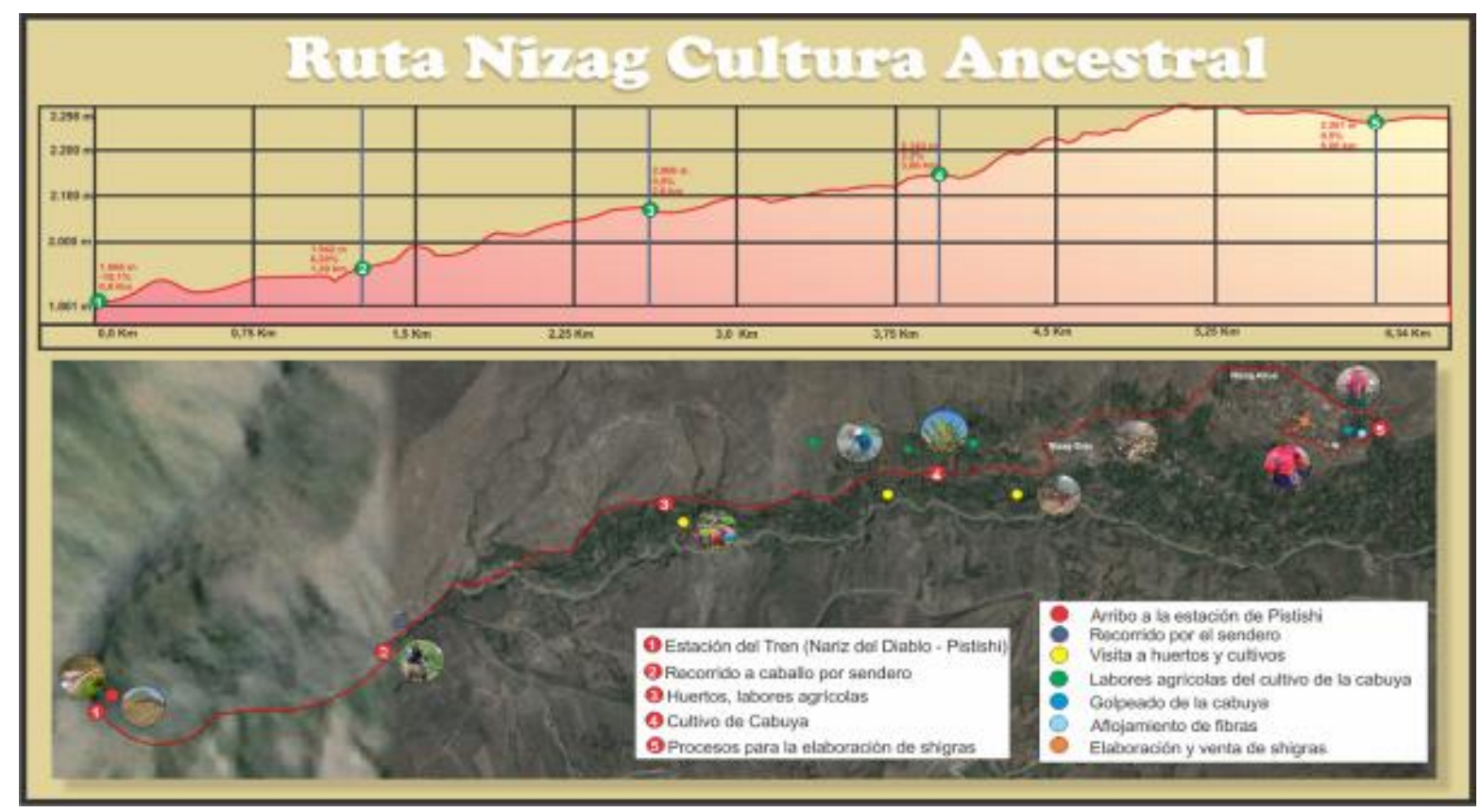

Figura 1. Propuesta de sendero Pistishi - Nizag

Fuente: (Bastidas A, 2014)

La operación del paquete turístico inicia en la estación del ferrocarril de Sibambe "Nariz del Diablo", sin embargo, el turista puede optar por un paquete en el que incluya el viaje en tren. Una tienda de venta de artesanías de la Asociación será el punto de encuentro para exponer las

\footnotetext{
${ }^{4}$ La señalética se establece de acuerdo a la norma técnica de señalización turística vigente a nivel nacional e internacional.

${ }^{5}$ Como atractivo turístico de importancia en la comunidad de Nizag se destaca el cerro Cóndor Puñuna conocido como la Nariz del Diablo y el cerro Chiripungo. Entre los elementos disponibles y relacionados al sistema agroturístico se encuentran: huertos frutales, medicinales y el cultivo de la cabuya.
} 
distintas clases y variedades de artesanías realizadas por las mujeres. La participación de los guías nativos de la comunidad brindará información histórica de Cóndor Puñuna o Nariz del Diablo.

Para la operación de lo descrito anteriormente, los costos del paquete turístico definidos demuestran la rentabilidad de la propuesta, tomando en cuenta una utilidad del $20 \%$ sobre los costos fijos y variables de operación y administración actuales, es así como para un pax el precio definido es de $\$ 240,22$; mientras que para un grupo de 10 pax el precio por persona es de $\$$ 84,24. Estos precios evidencian una rentabilidad del patrimonio cultural "artesanías en fibra de cabuya" como un producto integral en el cual participan los comuneros de acuerdo a actividades, funciones y experiencias dinamizando la economía local.

\subsection{Demanda Turística}

El análisis estadístico de los turistas que realizan la ruta en el tren de la nariz del Diablo se representan de acuerdo a los siguientes datos:

Tabla 1 Procedencia de los turistas en la Ruta del Tren Alausí - Sibambe (\%)

\begin{tabular}{ll|ll}
\hline \multicolumn{2}{l|}{$\begin{array}{l}\text { Turistas Extranjeros } \\
\text { 52,06 }\end{array}$} & \multicolumn{2}{l}{ Turistas Nacionales } \\
Procedencia & Porcentaje & Procedencia & Porcentaje \\
Región Europea & 77,37 & Pichincha & 47,43 \\
Norte América & 15,26 & Chimborazo & 24,00 \\
Sud América & 7.37 & Guayas & 28,57 \\
\hline Total & 100 & & 100 \\
\hline
\end{tabular}

Fuente: Encuesta a Turistas

Del 52,06\% de turistas extranjeros, el 77,37\% pertenecen a la Región Europea (Suiza, Bélgica, Alemania e Inglaterra), mientras que de Norte América corresponde al 15,26\% (Estados Unidos y Canadá) y finalmente Sudamérica representa el 7,37\% (Colombia, Brasil, Bolivia, Argentina, Perú y Chile). Ha de considerarse la estacionalidad de temporada y visitas de turistas, ya que, en el Ecuador continental, los arribos del mercado turístico dependen de los países emisores, considerando las facilidades o periodos de vacaciones del extranjero.

Mientras tanto, el turismo interno que corresponde al 47,94\% y que principalmente está presente en tres provincias, es decir, el 47,43\% son de la provincia de Pichincha, la provincia de Chimborazo promueve la participación del $24 \%$ de turistas y el $28,57 \%$ corresponde a turistas de la provincia del Guayas.

Tabla 2 Forma de Realizar el Viaje

\begin{tabular}{lll}
\hline Forma de Viaje & $\begin{array}{l}\text { Turistas Nacionales } \\
\text { Porcentaje }\end{array}$ & $\begin{array}{l}\text { Turistas Extranjeros } \\
\text { Porcentaje }\end{array}$ \\
\hline Grupo Organizado & 19,14 & 74,39 \\
Independiente & 72,22 & 22,22 \\
No responde & 8.64 & 3,39 \\
\hline Total & 100 & 100 \\
\hline
\end{tabular}

Fuente: Encuesta a Turistas 
Los turistas que hacen el recorrido Alausí-Sibambe tienen las siguientes formas de realizar su viaje: Los turistas Nacionales lo hacen en grupos organizados en 19,4\%, de forma independiente $72,22 \%$ y no responden a la pregunta el $8,64 \%$. Por su parte los turistas extranjeros realizan el viaje en grupos organizados en un $74,39 \%$, de forma independiente el $22,22 \%$, no responden a la pregunta $3,39 \%$

Como se puede observar en la tabla 2, existen diferencias importantes entre los turistas nacionales y los extranjeros para organizar los viajes, mientras que los turistas nacionales lo hacen mayoritariamente de forma independiente, los turistas extranjeros recurren a viajes organizados, de lo cual se deduce que los turistas en grupos organizados son el objetivo principal del proyecto, ya que es mucho más fácil organizar la operación dirigida.

Con respecto a la motivación del Viaje, las encuestas realizadas reportaron los siguientes datos:

Tabla 2 Motivación de viaje de los turistas en la Ruta del Tren Alausí - Sibambe (\%)

\begin{tabular}{lll}
\hline Motivación del Viaje & Turistas Nacionales & Turistas Extranjeros \\
\hline Vacaciones & 22,15 & 28,91 \\
Descanso & 21,46 & 27,95 \\
Convivencia cultural & 15,23 & 12,77 \\
Aventura & 15,95 & 16,94 \\
Negocios & 10,38 & 5,54 \\
Otras & 14,83 & 7,89 \\
\hline Total & 100 & 100 \\
\hline
\end{tabular}

Fuente: Encuesta a Turistas

Los resultados de la encuesta con respecto a la motivación se reflejan en los datos presentados en la tabla 2 en la que se establece que para el turista nacional las tres principales motivaciones de viaje fueron vacaciones $22,15 \%$, descanso, $21,46 \%$ y aventura el $15,95 \%$; coincidiendo con los turistas extranjeros con $28,91 \%$ vacaciones, $27,95 \%$ descanso y $16,94 \%$ aventura. La convivencia cultural, que es el área con mayor vinculación a la propuesta de Nizag se encuentra en cuarto puesto con $15,23 \%$ para el turismo nacional y el $12,77 \%$ para los turistas extranjeros.

Tabla 3 Disponibilidad de tiempo para la permanencia (\%)

\begin{tabular}{lll}
\hline & $\begin{array}{l}\text { Turistas } \\
\text { nacionales }\end{array}$ & Turistas extranjeros \\
\hline $\begin{array}{l}\text { Disponibilidad } \\
\text { tiempo }\end{array}$ & de Porcentaje & Porcentaje \\
Un día & 18.87 & 59,42 \\
Dos días & 28,93 & 25,61 \\
Tres días & 29,55 & 2,89 \\
Más de tres días & 17,62 & 4,36 \\
No responde & 5.03 & 7,72 \\
\hline Total & 100 & 100 \\
\hline
\end{tabular}

Fuente: Encuesta a Turistas 
La tabla 3 indica que los turistas nacionales tienen mayor disponibilidad de tiempo para permanecer en el atractivo con $29,55 \%$ por tres días, $28,93 \%$ por dos días, mientas que los turistas extranjeros proponen que su disponibilidad de tiempo es $59,42 \%$ para un día y $25,61 \%$ para dos días. Estos valores indican que si se quiere hacer turismo con extranjeros, la mejor opción es el de estructurar paquetes turísticos de un día, para prolongar la estadía es necesario contar con un producto con servicios de calidad, y ampliar la oferta hacia tour operadores de mayor importancia, para unirse, a través de una alianza estratégica con la operación del tren.

Si se hace posible la captación de turistas nacionales con paquetes de dos o más días es importante considerar que generalmente el este tipo de visitantes no planifican sus viajes con rigurosidad, por lo que resulta fácil acomodar su permanencia, siempre y cuando se le oferten alternativas que cubran sus expectativas.

Tabla 4 Presupuesto diario para actividad turística (\%)

\begin{tabular}{lll}
\hline Presupuesto & $\begin{array}{l}\text { Turistas nacionales } \\
\text { Porcentaje }\end{array}$ & $\begin{array}{l}\text { Turistas extranjeros } \\
\text { Porcentaje }\end{array}$ \\
\hline Menor a \$ 55 & $36,14 \%$ & $25.12 \%$ \\
Entre \$ 56 y \$76 & $23,24 \%$ & $46,85 \%$ \\
Entre \$77 y \$ 97 & $17,41 \%$ & $9,17 \%$ \\
Más de \$ 98 & $4,51 \%$ & $1,96 \%$ \\
No responde & $18,70 \%$ & $16.90 \%$ \\
\hline Total & $100 \%$ & $100 \%$ \\
\hline
\end{tabular}

Fuente: Encuesta a Turistas

Como indica la tabla 4, el Mayor porcentaje de turistas nacionales $36.14 \%$ manejan un presupuesto menor a $\$ 55$ dólares, seguido de $23,24 \%$ de turistas que tienen un presupuesto de entre \$56 a \$76 dólares diarios, para los turistas extranjeros el presupuesto diario que manejan es de entre $\$ 56$ a $\$ 76$ dólares con el $46,85 \%$ seguido de un presupuesto menor a $\$ 55$ con $25,12 \%$ : estos porcentajes indica que los presupuestos tanto para los nacionales como para los extranjeros se encuentran entre menos de $55 \%$ hasta $\$ 76$ dólares diarios.

Como la estadía de un visitante depende sobre todo de la disponibilidad de tiempo y la capacidad de gasto diaria, los datos antes analizados permitieron estructurar paquetes turísticos relacionados con estos dos factores, sumados a ellos el análisis de la forma, y la motivación del viaje y por supuesto el origen de los turistas. Con relación al presupuesto de los turistas es importante hacer notar que los gastos de los extranjeros como de los turistas nacionales son en dólares, este factor resulto decidor el momento del análisis para dar orientación al marketing del proyecto.

\section{Cadena de Valor turístico para la comunidad de Nizag}

Las artesanías elaboradas de fibras vegetales en el Ecuador son bastante diversas, y sus principales manifestaciones se dan en la costa y el austro ecuatoriano (Lugo M, Magal R, \& Shinn, 2015), haciendo que las elaborados de cabuya tengan una elevada competencia, sin 
embargo el valor intrínseco de los tejidos de fibra de cabuya en Nizag mantienen una vinculación más profunda con las raíces ancestrales de las mujeres artesanas (El Comercio, 2018), situación que en los otros casos se ha ido erosionando o transfigurando en emprendimientos semi artesanales, quitándole a los productos el encanto de la manufactura. Sin embargo, el problema está cuando la shigra sale de la comunidad para ser vendida en otros mercados, confundiéndose con productos similares y perdiendo su significancia cultural, de ahí que el producto tiene que y debe ser comercializado en la comunidad o en función de un mercadeo más elaborado y especializado.

Analizado el contexto de la producción de las shigras, y las peculiaridades de los potenciales turistas nacionales y extranjeros, así como las características de la ruta turística, es importante establecer las imbricaciones entre los recursos presentados en el contexto turístico para construir una cadena de valor del turismo para la comunidad.

Esta cadena de valor esta constituida por funciones, espacio territorial y economías en los que los actores se interrelacionan y van cumpliendo sus roles (Ceballos G, Zayas S, \& Martínez M, 2015). En las cadenas de valor turístico es trascendental la presencia de empresas y actores que participen en el mercado, esta dualidad genera vínculos y promueve nuevas alternativas de competitividad (Baños P \& Jiménez F, 2012). En las cadenas de valor turístico a más de los mercados y actores ofertantes es importante determinar la demanda final, ya que ella es la que elije desplazarse al destino ya sea directamente o con la ayuda de intermediarios.

De acuerdo a Bastidas (2012), en la cadena de valor turística de Nizag, se identifican las siguientes funciones: Mercado final, Operadoras y agencias de viajes extranjeras, agencias de viajes y operadoras nacionales, agencias de viajes y tour operadores locales, prestadores de servicios vinculados directa e indirectamente al turismo en el cantón Alausí, transporte, guías turísticos, prestadores de servicios del cantón Alausí el área de influencia, atractivos turísticos de la zona de influencia del destino, proyecto de turismo comunitario (Agroturismo de Nizag).

El diagrama de la Cadena de Valor (figura 2) para el proyecto de agroturismo de la comunidad de Nizag), permite hacer un análisis objetivo de la potencialidad del proyecto de Agroturismo vinculado a la cultura ancestral.

Por lo general, los emprendimientos turísticos de la Sierra Centro tienen graves problemas para consolidar mercados turísticos, recibiendo una mínima cantidad de visitantes, que en realidad no justifican los gastos que se suelen hacer por parte de las organizaciones auspiciantes de los proyectos. Esta escasa ocupación esta relacionada a la limitada vinculación vertical de la oferta turística y la bajo calidad de los servicios. Por otro lado, no se vinculan los potenciales atractivos que la comunidad puede ofrecer, siendo que el atractivo principal de la visita "la cultura ancestral" y que no se vincula con la naturaleza o la aventura.

En relación a los vínculos verticales de los proyectos turísticos comunitarios, en la actualidad ninguno de los reportados en la sierra centro tiene vinculación formal con agencias de tour operadores, solamente se lo hace de forma esporádica cuando, los turistas, sobre todo extranjeros, demandan este tipo de servicios, la forma en la que en la actualidad se logra captar clientes, es a través de las operadoras en la ciudad de Riobamba, que no manejan la logística de 
gestión necesaria como para hacer eficientes las conexiones con operadoras nacionales y mucho menos con operadoras internacionales. El mercado actual que se maneja, esta orientado a voluntarios y estudiantes de intercambio en el destino, siendo este un mercado de baja capacidad de solvencia.

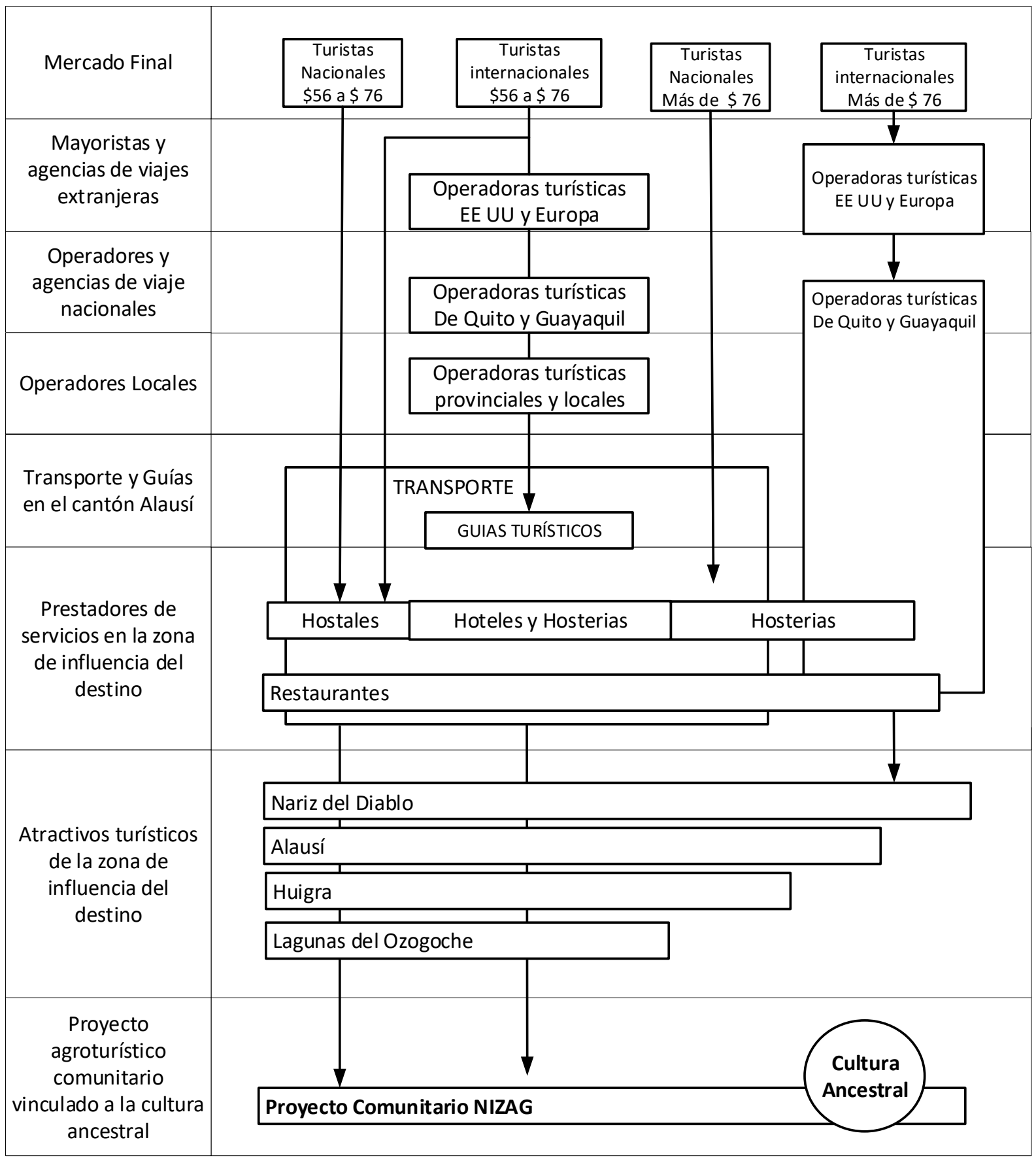

Figura 2: Cadena de valor Proyecto Agroturístico Nizag.

Fuente: (Bastidas A, 2012)

De acuerdo a la evaluación realizada por Bastidas (2014), la tarifa que se maneja para un paquete de dos días y una noche es de un promedio de $\$ 60$ dólares, que esta muy por debajo de 
la capacidad de pago de los turistas nacionales y extranjeros, en ella se incluyen tres comidas, alojamiento, actividades vivenciales en la comunidad, quedando una muy baja rentabilidad.

En relación a los vínculos horizontales, a pesar de que comunitariamente la organización es muy eficiente y activa, es solamente en el mantenimiento del orden político y social, pero adolece de graves defectos al momento de organizarse en la administración de emprendimientos, colectivos y más aún relacionados con la actividad turística. La organización escasamente se vincula o gestiona alianzas estratégicas con otros actores turísticos (prestadores de servidores turísticos) del entorno próximo, mucho menos con empresas externas.

La escasa vinculación vertical, limita la capacidad de mercado, esto debido a que la comunidad es reacia a dejarse ayudar de mejor manera por especialistas. Se ha detectado una impórtate injerencia de los organismos multilaterales que han intervenido en el sector, cada uno con sus propias ideas y criterios, dejando en la comunidad un alto grado de inseguridad. Por lo que ha sido complejo consolidar un producto estructuralmente sólido, las actividades agroturísticas y culturales son varias y están dispersas, debido a que los actores no han llegado a consensos y acuerdos.

De las propuestas actuales que dispone la comunidad de Nizag, no se ajustan a la demanda turística, ya que, tanto en la ciudad de Alausí como en otros cantones de la provincia de Chimborazo, los turistas disponen -generalmente- de un día para realizar actividades turísticas; a esto se suma la descuidada o no planificada infraestructura que ha sido construida sin considerar las realidades y necesidades de la demanda, sino más bien, en facilidades que son solicitadas por las comunidades para contar con un cierto tipo de "confort" para el turista, pero que dista de la realidad (en términos de facilidades, atractivos, actividades, idioma, entre otros.).

A los habitantes de Nizag no se les ha explicado adecuadamente cuáles son las dinámicas para sacar adelante un emprendimiento turístico por lo que han asumido la actividad como la solución a corto plazo de sus problemas económicos, esta forma de pensar afecta la sostenibilidad de las iniciativas turísticas de la comunidad a largo plazo, ya que al esperar resultados inmediatos y no tenerlos los comuneros pierden el interés.

Sin embargo, el agroturismo vinculado a la cultura ancestral es una extraordinaria oportunidad de negocio para la comunidad de Nizag, considerando que la comunidad mantiene inalterables sus recursos culturales y naturales, y un alto grado de asociatividad como rasgo propio de su identidad indígena.

En la actualidad, las mujeres han asumido importantes roles en la dirigencia comunitaria, y su injerencia en la toma de decisiones es cada vez mayor, en su intencionalidad existe una gran predisposición para trabajar en el mejoramiento del emprendimiento agroturístico vinculándole con las labores agrícolas y la producción artesanal de los tejidos de cabuya. Es importante por tanto trabajar en el mejoramiento de las relaciones verticales de la cadena de valor optimizando los vínculos entre la comunidad con los operadores, servidores turísticos y otros actores vinculados a la actividad.

Las relaciones horizontales en el espacio del proyecto agroturístico de Nizag, deben estar orientadas al mejoramiento de la calidad del producto ofertado, a través de la sistematización y organización de las actividades agropecuarias que realizan en la comunidad, los procesos 
culturales ancestrales y otras que se pudieran vincular al producto turístico. Por otro lado, se debe alcanzar un manejo adecuado e independiente de las finanzas del proyecto.

\section{Sostenibilidad social}

La estructuración horizontal de la cadena de valor del producto agroturístico de Nizag implica la participación de los distintos actores locales, de tal manera que los guías nativos y especializados, la prestación de servicios de alimentación y logística sean realizados por los miembros de la comunidad, asumiendo responsablemente las actividades a cumplir.

En este sentido el emprendimiento a logrado que: los guías nativos tengan las licencias correspondientes para la operación, se cuenta con el servicio de alquiler de caballo, el transporte turístico interno cumple con las normas de operación, el emprendimiento de restauración opera actualmente ofertando cocina tradicional, la Corporación de Mujeres Tejedoras participan en la elaboración de las artesanías y en la presentación de sus huertos familiares, este proceso integrador de la dinámica social de los comuneros implica sostenibilidad social y cultural.

La integración de la comunidad en las diferentes fases del emprendimiento y la participación activa aprovechando las capacidades individuales de los miembros da paso al empoderamiento del proyecto, generándose inquietud para formar parte de los procesos de aprendizaje, innovación y competitividad. En este sentido la actividad agroturística genera sinergias con la productividad de la comunidad y la valoración de cultura ancestral a través de la participación de todos los miembros que la integran, de forma especial las mujeres y los jóvenes.

\section{Conclusiones}

- Para las culturas indígenas, los recursos culturales ancestrales materiales e inmateriales, demuestran una relación entre el ser humano y la naturaleza, de ahí que tanto la cotidianidad de las comunidades, así como las expresiones de las formas de vida, permiten generar modelos de recuperación y aprovechamiento de éstos recursos culturales, por este motivo, la actividad turística se convierte en un modelo económico social de preservación de las identidades con un respeto a los pilares básicos del turismo comunitario, mostrando productos y servicios vinculados estrechamente a las formas de vida, transmitidas, en este caso, en las artesanías de fibra de cabuya.

- Nizag, por su particular ubicación geográfica y de sus orígenes étnicos, es poseedora de una singularidad riqueza natural, cultural y patrimonial, que, articulado a la actividad ferroviaria en la ruta Alausí - Sibambe, y la propuesta agroturística genera y diversifica nuevos productos turísticos con carácter cultural, ya que existe una simbiosis entre las prácticas agrícolas y el arraigo cultural. Del análisis económico, y la estructura de un paquete turístico del producto "artesanías en fibra de cabuya" se ha definido un valor de entre $\$ 84,24$ y $\$ 240,22$ pax/día dirigido principalmente a turista extranjero del continente Europeo y Norteamericano; ya que, la artesanía como tal, carece de un valor intrínseco. La actividad agroturística en sinergia con el patrimonio cultural material e inmaterial permite poner en valor los saberes ancestrales y formas de vida para la revalorización de los bienes culturales como testimonio vivo de la cultura ancestral de la comunidad. 
- El desarrollo del sistema agroturístico que permite y promueve la conservación del patrimonio cultural material -artesanías de cabuya (Fourcrosa andina)- corresponde a un proceso de análisis complejo sobre las potencialidades y actores de la comunidad que realizan prácticas de turismo, como un medio de coyuntura socio económico que busca un desarrollo productivo de la economía indígena, es por esto que, la cadena de valor turístico para la comunidad de Nizag demuestra un análisis objetivo de la potencialidad de las prácticas agrícolas con la cultura ancestral, en el que las relaciones horizontales (de la calidad) y verticales (con los actores), aspectos claves que permiten tener una sostenibilidad social, ya que integra la participación de la comunidad con el emprendimiento, principalmente de las mujeres y jóvenes como pilar fundamental de una economía colaborativa, justa e incluyente.

\section{Referencias Bibliográficas}

Baños P, J., \& Jiménez F, K. (2012). Propuesta de un modelo de competitiuvidad de destinos turísticos. Estudios y perspectivas en turismo, 21(4), 977-955. Obtenido de http://www.redalyc.org/articulo.oa? $\mathrm{id}=180724056010$

Bastidas A, B. (2012). Vinculación de los Procesos Productivos de las Artesanías en Fibra de Cabuya con la Actividad Turistica, en la Comunidad de Nizag, Parroquia la Matriz, Cantón Alausi, Provincia de Chimborazo en el Periodo 2011. Riobamba: UNACH.

Bastidas A, B. (2014). Diseño de un sistema Agroturistico para la conservación del patrimonio cultural de las artesanias de cabuya (Fourcrosa andina) de la comunidad de Nizag Parroquia la Matriz - Cantón Alausi. Guayaquil: Universidad Agraria del Ecuador.

Ceballos G, G., Zayas S, M., \& Martínez M, R. (2015). LA Cadena de valor como hilo conductore de la investigación en los destinos turísticos. Avances, 17(3), 3016-316.

Cedeño E, M., Pennington G, L., \& Matthews J, S. (2015). Preservación del patrimonio cultural para el desarrollo turístico. Turydes Revista Turiemo y Desarrollo, Digital.

Congreso Nacional del Ecuador. (2004). Ley de Patrimonio Cultural. En C. N. Ecuador, Constitución de la República del Ecuador (pág. 94). Quito.

Domínguez L, D., Batista R, M., \& Joseph L, C. (2014). Fundamentos Necsarios para alcanzar el desarrollo Socioeconómico Local A traves de la Gestión Turística Patrimonial. Revista de Estudios Sociales, 15(29), 17-32.

El Comercio. (26 de Septiembre de 2018). El documental de Robert Orozco retrata la importancia de los tejidos. Tendencias, pág. Digital .

Estrada A, G. (2015). El Turismo comunitario como estratégia de desarrollo local y mejoras en la condición de vida : Estudio de caso de la counidad de Nizag. Quito: FLACSO.

FEPTCE. (14 de 08 de 2013). Federación Plurinacional de Turismo Comunitario del Ecuador. Guía de Turismo Comunitario del Ecuador. Obtenido de www.feptce.org

Gómez E, J., \& Gómez, G. (2006). Saberes tradicionales agrícolas indigenas y campesinos: rescate, sistematización e incorporación a la IEA. $R A$ Ximhai, 2(2), 97-126.

INPC (a). (2013). Guía Metodológica para la Salvaguardia del Patrimonnio Cultural Inmaterial. Quito: Sobocgrafic.

INPC (b). (2013). Ficha de inventario de Técnicas Artesanales Tradicionales. En I. N. Cultural. Quito. 
Jimenez, D. (02 de 12 de 2014). Competitividad. Obtenido de http://djimene.blogspot.com/2013_05_01_archive.html

Lugo M, D., Magal R, T., \& Shinn, C. (2015). Ambiente y artesania: Sinergia para el desarrollo rural sostenible. Spanich Journal of Rural Development, 6(3-4), 57-64.

PDOT Alausí. (2015). Acvtualización del Plan de Ordenamiento territorial del cantón Alausí. Alausí: GAD Cantón Alausí.

Pilco C, C. (2015). Diseño de un Producto Turístico comunitario sostenible en la comunidad Nizag, cantón Alausí, provincia de Chimborazo. Riobamba: ESPOCH.

Rodas , M., Donoso, N., \& Sanmartín, I. (2015). El Turismo Comunitario en el Ecuador: Una Revisón de Literatura: Turismo, Desarrollo y Buen Vivir. Revista de Investigación de la Ciencia Turística RICIT, 9, 60-77.

Ruiz, E., Hernández, M., Coca, A., Cantero, P., \& Del Campo, A. (2008). Turismo comunitario en Ecuador. Comprendiendo el community-based tourism desde la comunidad. PASOS Revista de Turismo y Patrimonio Cultural, 399-418.

Urgiles P, L. (2016). Plan de Salvaguardia del patrimonio cultural de la comunidad Nizag, cantón Alausí, provincia de Chimboirazo. Riobamba: ESPOCH.

\section{【 Ciencia}




\section{PARA CITAR EL ARTÍCULO INDEXADO.}

Bastidas Aráuz, M. B., Inga Aguagallo, C. F., \& Fernández, D. F. (2020). El Agroturismo en sinergia con la preservación de los recursos culturales ancestrales. (El tejido de la fibra de cabuya en la comunidad de Nizag). ConcienciaDigital, 3(3.1), 58-74. https://doi.org/10.33262/concienciadigital.v3i3.1.1365

\section{Ligital}

El artículo que se publica es de exclusiva responsabilidad de los autores y no necesariamente reflejan el pensamiento de la Revista Conciencia Digital.

El artículo queda en propiedad de la revista y, por tanto, su publicación parcial y/o total en otro medio tiene que ser autorizado por el director de la Revista Conciencia Digital.

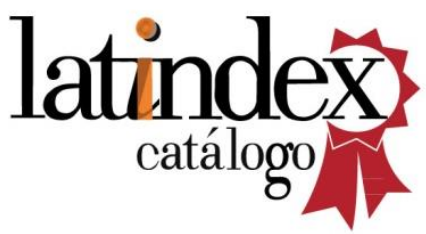

